\title{
Lipid Yield and Composition of Azolla filiculoides and the Implications for Biodiesel Production
}

\author{
Paul Brouwer ${ }^{1,2}$ - Adrie van der Werf ${ }^{3}$. Henriette Schluepmann ${ }^{1}$. \\ Gert-Jan Reichart ${ }^{2}$ - Klaas G. J. Nierop ${ }^{2}$
}

Published online: 19 August 2015

(C) The Author(s) 2015. This article is published with open access at Springerlink.com

\begin{abstract}
The aquatic fern Azolla is one of the fastestgrowing nitrogen-fixing plants on Earth and therefore considered as a potential source of biomass for bioenergy production. The lipid fraction from Azolla filiculoides was analyzed to investigate whether it suited biodiesel production. Since the productivity of Azolla is further increased at higher $\mathrm{CO}_{2}$ concentrations, $A$. filiculoides biomass was produced at $800 \mathrm{ppm}$ $\mathrm{CO}_{2}$ mimicking a cultivation system utilizing $\mathrm{CO}_{2}$ waste from industry. The harvested biomass contained $7.92 \pm 0.14 \%$ dry weight $(\mathrm{dw})$ crude lipids. Drying conditions did not significantly affect lipid composition or yields, indicating that drying conditions may be energetically optimized without the risk of product loss. Total lipid extracts contained $4.2 \pm 0.38 \%$ free fatty acids. Of the crude lipid fraction, $41 \pm 13 \%$ consisted of fatty acids that were converted into fatty acid methyl esters upon saponification in methanol. Unique mid-chain (di)hydroxy compounds constituted 7.2 $\pm 2.8 \%$ of the crude lipids. Based on the fatty acid profile, it was estimated that Azolla biodiesel meets requirements set by the EN14214 standard on fuel density, cetane number, and iodine value. The cold filter plugging point (CFPP), however, is expected to be
\end{abstract}

Electronic supplementary material The online version of this article (doi:10.1007/s12155-015-9665-3) contains supplementary material, which is available to authorized users.

Paul Brouwer

p.brouwer2@uu.nl

1 Molecular Plant Physiology, Utrecht University, Padualaan 8, 3584, CH Utrecht, Netherlands

2 Organic Geochemistry, Utrecht University, Heidelberglaan 2, 3584, CS Utrecht, Netherlands

3 Plant Research International, Droevendaalsesteeg 1, 6708, PB Wageningen, Netherlands too high due to relatively high concentrations of lignoceric acid and the presence of the mid-chain (di)hydroxy compounds. To produce high-quality biodiesel from Azolla lipids, therefore, a fractionation step will be required removing these compounds. As an advantage, the long-chain alcohols and (di)hydroxy fatty acids obtained after fractionation may provide a valuable secondary product stream with applications to chemical industry and nutrition.

Keywords Azolla $\cdot$ Fern $\cdot$ Lipids $\cdot$ Feedstock $\cdot$ Biodiesel · Biochemicals

\section{Introduction}

Since fossil resources are finite and their large-scale use as fuels has a negative impact on global climate, alternative resources for energy and materials are needed. It is expected that, with the depletion of fossil resources, plants will need to provide an important proportion of our requirements for fuels and chemicals [1].

However, not all plant-based alternatives are equally sustainable. Current biodiesel feedstocks, i.e., soybean, rapeseed, palm, and sunflower oil, suffer from low land use efficiency, high input requirement [2], and competition for arable land with food production. Hence, to produce fuels and chemicals in a more sustainable way, novel crops are sought that are lowinput, land-efficient, and highly productive. The floating water fern Azolla is one such potential novel crop. It can be cultivated in closed systems on non-arable land or in natural occurring freshwater basins. It is known for its high growth rates: In a 154-day outdoor growth experiment, Becerra et al. [3] estimated the annual productivity of Azolla filiculoides to be $39 \mathrm{t}$ dry weight per hectare. Moreover, Azolla reaches high growth rates without inorganic nitrogen in its growth medium 
[4], due to its symbiotic relationship with nitrogen-fixing cyanobacteria (Nostoc azollae). Active $\mathrm{CO}_{2}$ supply may increase the productivity of Azolla even further by $53 \%$ at $760 \mathrm{ppm} \mathrm{CO} \mathrm{CO}_{2}$ compared to that at $340 \mathrm{ppm}$ [5].

Until now, Azolla has been applied as biofertilizer in rice paddy fields, investigated as a biosorbent of heavy metals [6], and evaluated as raw animal feed [7-9]) or protein feed [10]. For biofuel or bioenergy production, so far, anaerobic fermentation to produce biogas $[11,12]$ and pyrolysis of whole Azolla biomass have been suggested [28].

In the present study, we focus on the lipid fraction of Azolla as a source of biodiesel. The lipid fraction contains esterbound fatty acids (FAs) which may be converted into biodiesel using standard alkaline trans-methylation. Biodiesel quality can be predicted from the FA profile of the feedstock [13]. Therefore, various researchers have developed, and used, numerical models to estimate biodiesel quality indicators including density, cetane number, iodine value, and cold filter plugging point (CFPP), using FA profiles [14-19]. To assess the quality of biodiesel produced from Azolla using these numerical models, quantitative information on its lipid composition is required.

Existing reports on Azolla lipids either were incomplete [20] or did not focus on compound quantification [21]. Therefore, we aimed to analyze all major lipids of $A$. filiculoides. To mimic the situation in a production system utilizing $\mathrm{CO}_{2}$ waste, biomass was obtained from productive cultures grown at two times the atmospheric $\mathrm{CO}_{2}$ concentration, i.e., $800 \mathrm{ppm}$ $\mathrm{CO}_{2}$, comparable to Speelman et al. [5].

Quantification of compounds derived from dried biomass may be affected by the drying condition [22]. Since Azolla is an aquatic crop with a high water content, drying will be a likely step in any biomass processing system and needs to be performed with the least energy costs, without affecting extractability and composition of lipids. Therefore, this study first investigates the lipid yields and composition of A. filiculoides in relation to drying conditions. Second, we evaluate the implications for biodiesel production, using numerical models to estimate biodiesel quality.

\section{Materials and Methods}

\section{Biomass Production and Pre-treatment}

A. filiculoides was obtained from the International Rice Research Institute (IRRI) under accession number 1052. Details on the original site of collection are provided in the IRRI germplasm collection catalogue [23]. Plants were cultivated in a growth chamber at Wageningen University. Growth in continuous culture was performed, in five separate $30-\mathrm{L}$ containers, at a $\mathrm{CO}_{2}$ concentration of $800 \mathrm{ppm}$, a day/night temperature of $23 / 20^{\circ} \mathrm{C}$, a 16 -h day length, and a photosynthetic flux density of $325 \mu \mathrm{mol} \mathrm{m} \mathrm{s}^{-1}$. Fresh nutrients were supplied every 3 days with the following concentrations: $0.7 \mathrm{mM}$ $\mathrm{KNO}_{3}, 0.1 \mathrm{mM} \mathrm{Ca}\left(\mathrm{NO}_{3}\right)_{2}, 0.13 \mathrm{mM} \mathrm{KH}_{2} \mathrm{PO}_{4}$, and $0.1 \mathrm{mM}$ $\mathrm{MgSO}_{4} \cdot 7 \mathrm{H}_{2} \mathrm{O}$ of macronutrients and $4.7 \mu \mathrm{M}$ Fe-EDTA, $2.2 \mu \mathrm{M} \mathrm{MnSO}_{4} \cdot \mathrm{H}_{2} \mathrm{O}, 0.1 \mu \mathrm{M} \mathrm{Na}_{2} \mathrm{Mo}_{4} \cdot 2 \mathrm{H}_{2} \mathrm{O}, 8.1 \mu \mathrm{M} \mathrm{H}_{3} \mathrm{~B}_{3}$, $0.06 \mu \mathrm{M} \mathrm{CuSO}_{4} \cdot 5 \mathrm{H}_{2} \mathrm{O}$, and $3.1 \mu \mathrm{M} \mathrm{ZnSO} \cdot 5 \mathrm{H}_{2} \mathrm{O}$ of trace elements.

The entire medium was refreshed every 2 weeks. Every 3 or 4 days, one third of the surface area of each container was harvested. From all five containers, a batch of fresh Azolla biomass was harvested for the analysis. Each batch was divided into three aliquots which were dried for 3 days at $30{ }^{\circ} \mathrm{C}$, dried for 1 day at $65^{\circ} \mathrm{C}$, or freeze-dried, respectively. After drying, the biomass was ground using a Retsch ZM200 grinder equipped with a $1-\mathrm{mm}$ sieve.

To determine the dry weight of each aliquot after drying and grinding, $1 \mathrm{~g}$ of biomass was pre-weighed in alumina cups, which were placed into an oven set at $105^{\circ} \mathrm{C}$. They were left to dry for $24 \mathrm{~h}$ after which they were transferred into an exsiccator. After cooling for $1 \mathrm{~h}$ inside the exsiccator, the alumina cups were taken out and immediately weighed using a Bosch SAE 200 scale with a sensitivity of $0.1 \mathrm{mg}$.

\section{Total Lipid Extraction and Saponification}

The freeze-dried and ground Azolla biomass was Soxhletextracted with a 7.5:1 dichloromethane (DCM) to methanol $(\mathrm{MeOH})$ solution for $24 \mathrm{~h}$. The collected extracts were dried using a rotary evaporator and weighed to determine the amount of "crude lipids" obtained. Subsequently, these total lipid extracts (TLEs) were re-dissolved in 9:1 DCM/MeOH and ran over a $\mathrm{Na}_{2} \mathrm{SO}_{4}$ column to remove any traces of water. Afterward, the TLEs were dried under continuous nitrogen flow.

For TLE analysis, an aliquot was methylated using diazomethane at room temperature, which was subsequently purified over a silica (60-Å pore size) column. Next, the extract was silylated by bis(trimethylsilyl)trifluoroacetamide (BSTFA) in pyridine at $60{ }^{\circ} \mathrm{C}$ for $20 \mathrm{~min}$. Five to ten micrograms of squalane was added as an internal standard.

A selection of lipid extracts was saponified in $2 \mathrm{~N} \mathrm{KOH}$ in $\mathrm{MeOH}(96 \%)$ at $70{ }^{\circ} \mathrm{C}$ for $2 \mathrm{~h}$. After this, the solution was acidified to $\mathrm{pH}<5.5$ using $2 \mathrm{~N} \mathrm{HCl}$. One milliliter of ultrapure water (from Milli-Q water purifier) was added, and the solution was three times extracted by $1 \mathrm{ml}$ of DCM. The DCM fractions were combined and dried under continuous nitrogen flow. From these saponified extracts (SEs), traces of water were removed using a $\mathrm{Na}_{2} \mathrm{SO}_{4}$ column, after which the same derivation steps were conducted as for the TLEs.

Lastly, TLEs and SEs were run on a Hewlett Packard Gas Chromatograph-Flame Ionization Detector (GC-FID) and Thermo-Finnigan TraceGC ultra-Trace DSQ Gas Chromatograph-Mass Spectrometer (GC-MS). Both machines were 
equipped with a Varian CP-Sil5CB column $(30 \mathrm{~m}, 0.32 \mathrm{~mm}$ i.d., and film thickness of $0.10 \mu \mathrm{m})$. The $\mathrm{GC}$ was operated at constant pressure of $100 \mathrm{kPa}$, whereas the GC-MS was operated at constant flow of $1.6 \mathrm{ml} \mathrm{min}{ }^{-1}$. Temperature profiles were identical for each analysis, i.e., $70{ }^{\circ} \mathrm{C}$ during on-column injection, increasing to $130{ }^{\circ} \mathrm{C}$ at a rate of $20^{\circ} \mathrm{C} \mathrm{min}^{-1}$, then increasing to $320{ }^{\circ} \mathrm{C}$ at a rate of $4{ }^{\circ} \mathrm{C} \mathrm{min}{ }^{-1}$, and finally, an isothermal hold for $20 \mathrm{~min}$. The MS operated within a scanning range of $m / z 50-800$.

Identification of the compounds was carried out by their mass spectra using a NIST library or by interpretation of the spectra, by their retention times, and/or by comparison with literature data. Quantification was conducted by integration of peak areas of each individual peak/compound relative to that of the internal standard. In the case of co-eluting peaks, peak separation was achieved by comparing relative intensities of specific fragment ions and using their ratio to quantify each of the compounds identified. Dotriacontane was added as a tracer before Soxhlet extraction to analyze losses during the extraction and subsequent workup procedure and allow to correct compound concentrations obtained from GC and GC-MS analysis. In total, 11 TLEs were analyzed, 4 of which were extracted from biomass batches dried at $30{ }^{\circ} \mathrm{C}, 4$ extracted from batches dried at $65{ }^{\circ} \mathrm{C}$, and 3 extracted from freeze-dried batches. Nine SEs were analyzed, three for each drying condition.

\section{Analysis of Variance}

To determine whether drying conditions affect lipid yields and composition, a one-way analysis of variance (ANOVA) was performed using SPSS 20 statistics software. As we were interested in the specific effect of predefined drying conditions, i.e., freeze-dried, 3 days at $30{ }^{\circ} \mathrm{C}$, and 1 day at $65{ }^{\circ} \mathrm{C}$, we used a straightforward fixed effects model:

$\gamma_{\mathrm{ij}}=\mu+\alpha_{\mathrm{i}}+\varepsilon_{\mathrm{ij}}$

where $\gamma_{\mathrm{ij}}=$ lipid or compound concentration (\%), $\mu=$ common value, $\alpha_{\mathrm{i}}=$ treatment effect, and $\varepsilon_{\mathrm{ij}}=$ residual error due to variation between biomass batches and variations introduced during analysis. For determining the effect of drying conditions on crude lipid yield, all five replicates were used $(j=5)$, whereas for determining the effect of drying conditions on individual compounds, a random subset of at least three replicates were used $(j=3)$. For individual compounds, computing was done on the basis of normalized concentrations to eliminate the effect of the variance in total compound detection. In cases that the $F$ test provided a value with $p<0.05$, Tukey's test was used to determine which drying condition showed significant deviation.

\section{Estimation of Biodiesel Properties}

Fatty acid methyl ester (FAME) composition was used to estimate biodiesel properties, i.e., density, cetane number, iodine value, and cold filter plugging point (CFPP) of Azolla biodiesel. To estimate these properties, numerical models are available in the literature. The density ( $\rho$ ) was calculated by Eq. (1) by assuming a perfect mixture of FAMEs. The densities of pure FAMEs were estimated using Eq. (2) [16]:

$\rho_{\mathrm{B}}=\sum X_{\mathrm{i}} \rho_{\mathrm{i}}$

$\rho_{\mathrm{i}}=851.471+\frac{250.718 d b+280.899-92.180(m-1)}{1.214+n}$

where $X_{\mathrm{i}}=$ relative content of the FAME (\%), $d b=$ number of double bonds in the FAME, $m=$ number of carbon atoms in the alcohol used for esterification, and $n=$ number of carbon atoms in the original fatty acid. Similarly, the cetane number (CN) is calculated in Eq. (3) by assuming a perfect mixture of FAMEs, and cetane numbers of pure FAMEs are estimated using the formula in Eq. (4) [15]:

$C N_{\mathrm{B}}=\sum X_{\mathrm{i}} C N_{\mathrm{i}}$

$C N_{\mathrm{i}}=-21.157+\left(7.965-1.785 d b+0.235 d b^{2}\right) n-0.099 n^{2}$

where $C N_{\mathrm{B}}=$ cetane number of the blend and $C N_{\mathrm{i}}=$ cetane number of pure FAME. Iodine value and cold filter plugging point were estimated using formulas derived by Ramos et al. [14]. Equation (5) provides the iodine value as a function of the degree of unsaturation (DU), whereas DU is given by Eq. (6) [14]:

Iodine value $=87.396 \cdot D U+1.6691$

$D U=($ monosaturated $C n: 1, w t . \%)$

$$
+2 \cdot(\text { polysaturated } C n:>1, w t . \%)
$$

The CFPP was estimated with Eq. (7) using the long chain saturation factor $\operatorname{LCS} F(A)$, as defined in Eq. (8) [14]:

$C F P P=8.9243 \cdot \operatorname{LCSF}(A)-19.325$

$$
\begin{aligned}
\operatorname{LCSF}(A)= & M P_{C 18} \cdot C 18(w t . \%)+M P_{C 20} \cdot C 20(w t . \%)+ \\
& M P_{C 22} \cdot C 22(w t . \%)+M P_{C 24} \cdot C 24(w t . \%)
\end{aligned}
$$

where $M P_{\mathrm{i}}=$ melting point of the saturated FAME (in degrees Celsius).

For comparison with other biodiesel feedstocks, cetane number, iodine value, and CFPP of rapeseed, soybean, and palm were obtained from Ramos et al. [14], whereas reported FAME distributions were used to calculate biodiesel density. For the green algae Scenedesmus incrassatulus, all biodiesel parameters were calculated using the FAME distribution 
reported by Arias-Peñaranda et al. [17]. European standards for biodiesel properties were drawn from EN 14214 [24].

\section{Results and Discussion}

\section{Lipid Yield, General Composition, and Effects of Drying Conditions}

Cultures of $A$. filiculoides grown at $800 \mathrm{ppm} \mathrm{CO}_{2}$ had an average productivity of $13.24 \mathrm{~g} \mathrm{~m}^{-2}$ day $^{-1}$ over a period of 40 days. The harvested biomass was either dried for 3 days at $30{ }^{\circ} \mathrm{C}$, dried for 1 day at $65{ }^{\circ} \mathrm{C}$, or freeze-dried, before lipid extraction. Table 1 provides the crude lipid yields from biomass dried at each of these conditions. Small differences were observed between drying conditions, but differences between groups were not found to be significant by ANOVA as shown in Table 2. The average crude lipid yield of all extractions equals $7.92 \pm 0.14 \%$ of the dry weight (dw).

Online Resource 1 provides the average compound concentrations of the TLEs and SEs. Based on the SEs, 4.6 \pm $1.4 \% \mathrm{dw}$ of lipids could be accounted for using quantification on the GC/GC-MS, whereas only $0.84 \pm 0.40 \% \mathrm{dw}$ of lipids are detected in TLEs. Differences between the TLEs and the SEs are summarized in Fig. 1 for all major (groups of) compounds in Azolla. Saponification in methanol converted the ester-bound fatty acids into fatty acid methyl esters (FAMEs). Similarly, phytol was derived from chlorophyll upon saponification. The amount of sterols did not change significantly. Saponification further resulted in the detection of higher amounts of mid-chain (di)hydroxy compounds, due to the hydrolysis of esters of C26-C36 (di)hydroxy fatty acids ((di)OH FAs).

Variations in the concentrations of individual compounds can mainly be explained by the variation in total compound detection, as indicated by the much lower variations in normalized concentrations. The ANOVA test only showed a significant $(p<0.05)$ difference between drying conditions for 9 , 10-dihydroxynonacosane (C29 20,21( $\omega 9, \omega 10)$ diol) in TLEs and phytol in SEs, as indicated with an asterisk in Online Resource 1. All results of the ANOVA test on TLEs and SEs

Table 1 Crude lipid yield of Azolla batches exposed to different drying conditions and results of analysis of variance

\begin{tabular}{lll}
\hline Drying condition & $N$ & Crude lipid yield $(\% \mathrm{dw})$ \\
\hline $30{ }^{\circ} \mathrm{C}, 3$ days & 5 & $7.75 \pm 0.49$ \\
$65{ }^{\circ} \mathrm{C}, 1$ day & 5 & $7.94 \pm 0.22$ \\
freeze drying, 3 days & 5 & $8.16 \pm 0.30$ \\
Average & 5 & $7.92 \pm 0.14$
\end{tabular}

$N$ denotes the number of replicates. Crude lipid yield is given as average \pm standard deviation
Table 2 Results of analysis of variance (ANOVA) in crude lipid yield

\begin{tabular}{llllll}
\hline & $\begin{array}{l}\text { Sum of } \\
\text { squares }\end{array}$ & $\begin{array}{l}\text { Degrees of } \\
\text { freedom }\end{array}$ & $\begin{array}{l}\text { Mean } \\
\text { square }\end{array}$ & $F$ & $p$ value \\
\hline Between groups & $4.53 \cdot 10^{-5}$ & 2 & $2.27 \cdot 10^{-5}$ & 1.936 & .187 \\
Within groups & $1.40 \cdot 10^{-4}$ & 12 & $1.17 \cdot 10^{-5}$ & & \\
Total & $1.86 \cdot 10^{-4}$ & 14 & & & \\
\hline
\end{tabular}

$F$ provides the result of the Fisher test. The $p$ value gives the likelihood of the found $F$ value for the given degrees of freedom

are provided in Online Resource 2. For SEs, most phytol was detected in batches dried at $65{ }^{\circ} \mathrm{C}$ and least in freeze-dried batches. This may indicate that extraction of chlorophyll and derivatives is less efficient from freeze-dried material. Overall, the effect of drying conditions on the lipid yield and composition appears to be of minor importance within the scope of this study. Therefore, it was decided not to distinguish between drying conditions for the further analysis.

\section{Fatty Acid Distribution}

The FAs were estimated to constitute $3.2 \pm 1.0 \% \mathrm{dw}$ of Azolla biomass and $41 \pm 13 \%$ of the crude lipid fraction. The average FA profiles of TLEs and SEs of Azolla are given in Fig. 2. Palmitic acid (C16:0 FA), linoleic acid (C18:2 FA), and linolenic acid (C18:3 FA) are by far the dominating FAs. Furthermore, the concentration of lignoceric acid (C24:0 FA) in Azolla is relatively high compared to that in other plant species, such as soy, palm, and rapeseed [14].

In TLEs, free fatty acids (FFAs) amounted to $4.2 \pm 0.38 \%$ of the crude lipid fraction. Many of the FAs identified in SEs could not be detected in TLEs. These include pentadecylic acid (C15:0 FA), palmitoleic acid (C16:1 FA), hexadecatrienoic acid (C16:3), arachidic acid (C20:0 FA), eicosatrienoic acid (C20:3 FA), nervonic acid (C24:1 FA), and cerotic acid (C26:0 FA).

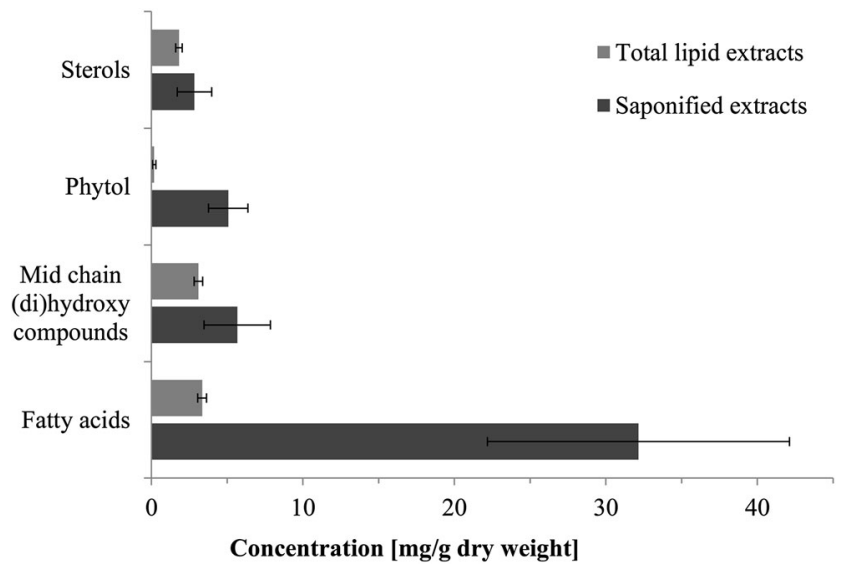

Fig. 1 Concentrations of major (groups of) compounds. Error bars indicate standard deviation ( $N=5, N=4$ for TLEs and SEs, respectively) 
Fig. 2 Fatty acid concentrations in TLEs and SEs. Error bars indicate the standard deviation, $N=5$ for TLEs and $N=4$ for SEs

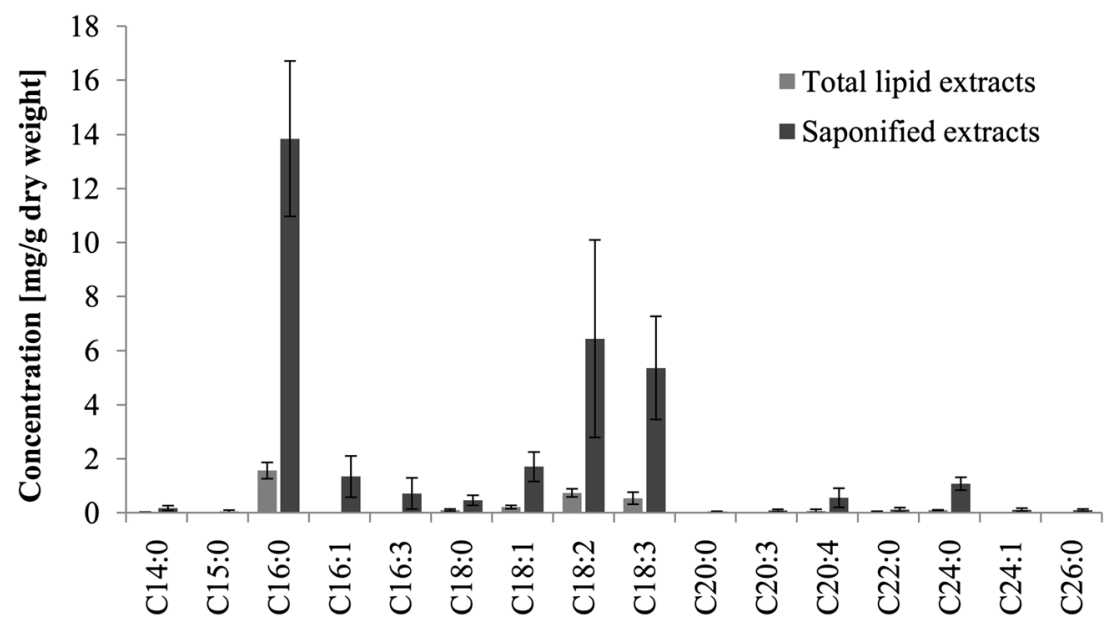

\section{Mid-chain (Di)hydroxy Compounds}

The mid-chain (di)hydroxy compounds in Azolla are characterized by their long chain, i.e., 26 to 52 carbon atoms, and the presence of at least one mid-chain hydroxy group located at either the $\omega 20$ or $\omega 9$ position on the carbon chain. This allows the methyl and trimethylsilyl (TMS) derivatives to be identified using typical fragment ions at $\mathrm{m} / \mathrm{z} 369$ and $\mathrm{m} / \mathrm{z}$ 215, respectively [21]. As illustrated in Fig. 3, they can be further subdivided in (di)OH alkanes and (di)OH alcohols, and (di)OH FAs and (di)OH wax esters. For each of these classes, examples of structural formulas are given in Fig. 3a-h. The (di)OH alkanes consist of alkanols and diols with solely mid-chain hydroxy groups and thus have an alkane backbone. In contrast, the (di)OH alcohols are diols and triols, both have a hydroxy group at the 1 position as midchain hydroxy group(s) and are therefore termed (di)OH alcohols. Similarly, the (di)OH fatty acids possess a carboxylic acid group at the 1 position and mid-chain hydroxy group(s). All (di)OH wax esters identified are palmitate esters of (di)OH alcohols. Four of the mid-chain (di)hydroxy compounds identified were not previously reported [21]. In Online Resource 3, the mass spectra of the methyl ester and TMS ethers of these compounds are displayed. Some compounds identified by Speelman et al. [21] were not detected in the TLEs or in SEs, including 7-hexacosanol (C26 7( 220$)$ alkanol), 9octacosanol (C28 ( $\omega 20)$ alkanol), and 17 hydroxyhexadotriacontane palmitate ester (C52 ( $\omega 20) \mathrm{OH}$ wax ester). Small quantities of odd-numbered $\mathrm{OH}$ FAs were detected but provided too little signal to be quantified.

In Fig. 3i, the concentrations are summarized for all types of mid-chain (di)hydroxy compounds. In TLEs, $0.31 \pm 0.028 \% \mathrm{dw}$ of mid-chain (di)hydroxy compounds were detected, consisting of even amounts of (di)OH alkanes and (di)OH alcohols and a slightly lower amount of (di)OH wax esters. The most abundant compounds in TLEs are the 20,21-dihydroxynonacosane palmitate ester
(C45 ( $\omega 9, \omega 10)$ diOH wax-esters) and the C29 20,21( $\omega 9$, $\omega 10)$ diol.

In SEs, the mid-chain (di)hydroxy compounds amounted to $0.57 \pm 0.22 \% \mathrm{dw}$ of the biomass and $7.2 \pm 2.8 \%$ of the crude lipid fraction, respectively. Upon saponification, the (di)OH wax esters were efficiently hydrolyzed, which is apparent from their absence from SEs and the increase in the concentration of their breakdown products: C16:0 FA and (di)OH alcohols, i.e., C30-C34 1, $\omega 20$ diols, C30-C32 1, $\omega 20, \omega 21$ triols, and in particular, 1,20,21-nonacosanetriol (C29 1,20, $21(1, \omega 9, \omega 10)$ triol). Surprisingly, (di)OH FAs turned out to be the dominant compounds in SEs, whereas in the TLEs, only C29 20,21 ( $\omega 9, \omega 10)$ diOH FA was faintly detected. The increase in (di)OH FAs after saponification suggests that they are part of lipid esters that are too large to be GC amendable and thereby undetected in TLEs. The estimated mass of all (di)OH FAs was approximately $0.22 \pm 0.092 \% \mathrm{dw}$. Overall, the compounds with a hydroxy group at position $\omega 20$ occur in more diverse chain lengths compared to the compounds with hydroxy groups at positions $\omega 9$ and $\omega 10$, whereas both types occur in equal amounts.

\section{Implications for Biodiesel Production}

The ester-bound FAs are by far the dominant lipids in A. filiculoides, i.e., $3.1 \pm 1.0 \%$ dw. Other Azolla species might have a higher lipid content, such as $A$. caroliniana, for which a crude lipid fraction of $12.7-16.4 \% \mathrm{dw}$ was reported [20]. However, this difference may as well be caused by adjustment of the biomass composition to the growth rate and/or a shift in carbon allocation under high $\mathrm{CO}_{2}$ concentrations, as observed in higher plants [25]. Due to its continuous productivity, considerable amount of oil can be produced from an Azolla production system on an annual basis. In a controlled production system with active $\mathrm{CO}_{2}$ supply, we achieved an oil production equivalent to $1500 \mathrm{~kg} \mathrm{ha}^{-1}$ year $^{-1}$. In an outdoor system, Becerra et al. [3] obtained a biomass productivity of 39, 
Fig. 3 a-h Examples of structural formulas of each compound type and class: a $12-$ hentriacontanol (C31 12(w20) alkanol), b 9,10-

dihydroxynonacosane (C29 $20,21(\omega 9, \omega 10)$ diol $),$ c 1,13dotriacontanediol (C32 1,13 $(1, \omega 20)$ diol $), \mathbf{d} 1,20,21$ nonacosanetriol (C29 1,20,21 $(1, \omega 9, \omega 10)$ triol $),$ e 11hydroxytriacontanoic acid (C30 11(w20) OH FA), f 20,21dihydroxynonacosanoic acid (C29 20,21( $\omega 9, \omega 10)$ diOH FA), g 11-hydroxytriacontane palmitate ester $(\mathrm{C} 46(\omega 20) \mathrm{OH}$ wax ester), h 20,21dihydroxynonacosane palmitate ester $(\mathrm{C} 45(\omega 9, \omega 10) \mathrm{diOH}$ wax ester). i Concentrations of major classes of mid-chain (di)hydroxy compounds in TLEs and SEs. Error bars indicate the standard deviation, $N=5$ for TLEs and $N=$ 4 for SEs

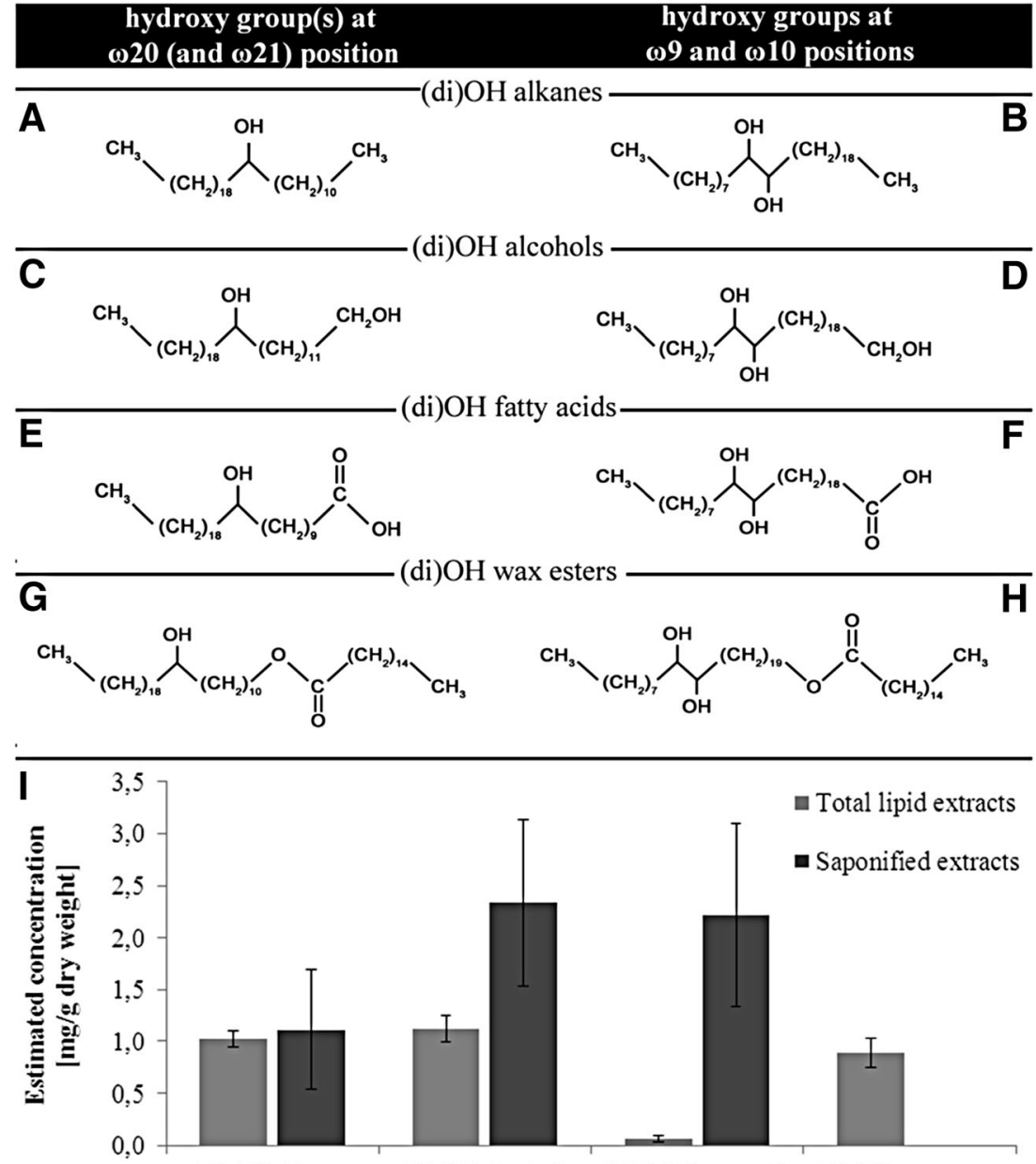

(di) $\mathrm{OH}$ alkanes (di)OH alcohols (di) $\mathrm{OH}$ fatty acids (di) $\mathrm{OH}$ wax esters
$000 \mathrm{~kg} \mathrm{ha}^{-1}$ year $^{-1}$, corresponding to an oil production of approximately $1200 \mathrm{~kg} \mathrm{ha}^{-1}$ year ${ }^{-1}$, assuming a similar lipid content. Common biodiesel feedstocks such as soybean, rapeseed, and palm have annual oil productivity of 406, 1307, and $5462 \mathrm{~kg} \mathrm{ha}^{-1}$ year $^{-1}$, respectively [26]. As an example of other novel biodiesel sources, the annual oil productivity of the microalgae $S$. incrassatulus can be estimated between 2300 and $3900 \mathrm{~kg} \mathrm{ha}^{-1}$ year $^{-1}$, mainly depending on annual productivity [27]. Hence, with oil as the sole product, Azolla cultivation is likely outcompeted by palm oil and microalgae. Utilizing whole Azolla biomass can yield higher amounts of bioenergy. Muradov et al. [28] obtained $33 \%$ of biooil after pyrolysis of whole Azolla biomass that can be directly used as diesel fuel supplement. In their approach, all biomass components, including protein, polyphenols, and carbohydrates, are converted into pyrolysis products. The advantage of using only the lipid extract for biodiesel production is that other biomass components can be extracted separately and commercialized as higher-value products. This holds in particular for the protein fraction which is a major (20-25\%) component of Azolla biomass and potentially valuable as feed [8-10]. If we compare Azolla to current protein crop soy, the amount of biodiesel that can be produced from the Azolla lipid fraction is nearly three times higher.

Production of biodiesel from Azolla lipids will require a conversion process that tolerates a high FFA content. As with many other biodiesel feedstocks, the FFA content of Azolla, i.e., $4.2 \pm 0.38 \%$, is higher than the limit, i.e., $2.5 \%$, for basecatalyzed conversion [29]. The FFA content can be reduced by using acid-catalyzed methylation of the FFAs prior to alkaline hydrolysis [30]. Alternatively, high FFA tolerating methylation methods can be employed, such as the use of sulphonated synthetic carbon catalysts [31].

Biodiesel quality indicators - density, cetane number, iodine value, and cold filter plugging point (CFPP) — estimated using FA profile and available numerical models are provided in Fig. 4, along with (estimated) values for a selection of other biodiesel sources and the limits set by the EN 14214 standard. Values were calculated from the average fatty acid profile in SEs $(n=4)$. The biodiesel has an estimated density of $880 \pm$ $2.9 \mathrm{~kg} \mathrm{~m}^{-3}$, a cetane number of $63 \pm 4.0$, and an iodine value of $80 \pm 15$. The values are all well within limits set by the EN 14214 standard. Although no European-wide limits are provided for the CFPP, it can be seen that the estimated CFPP for 
Fig. 4 Estimated density, cetane number, iodine value, and cold filter plugging point (CFPP) for biodiesel derived from Azolla compared to other feedstock sources. Dotted lines indicate limits set by the EN 14214 European standard. Parameters for rapeseed, soybean, and palm were taken from Ramos et al. [14] and parameters for green algae (Scenedesmus incrassatulus) were calculated from the fatty acid distribution obtained from Arias-Peñaranda et al. [17]
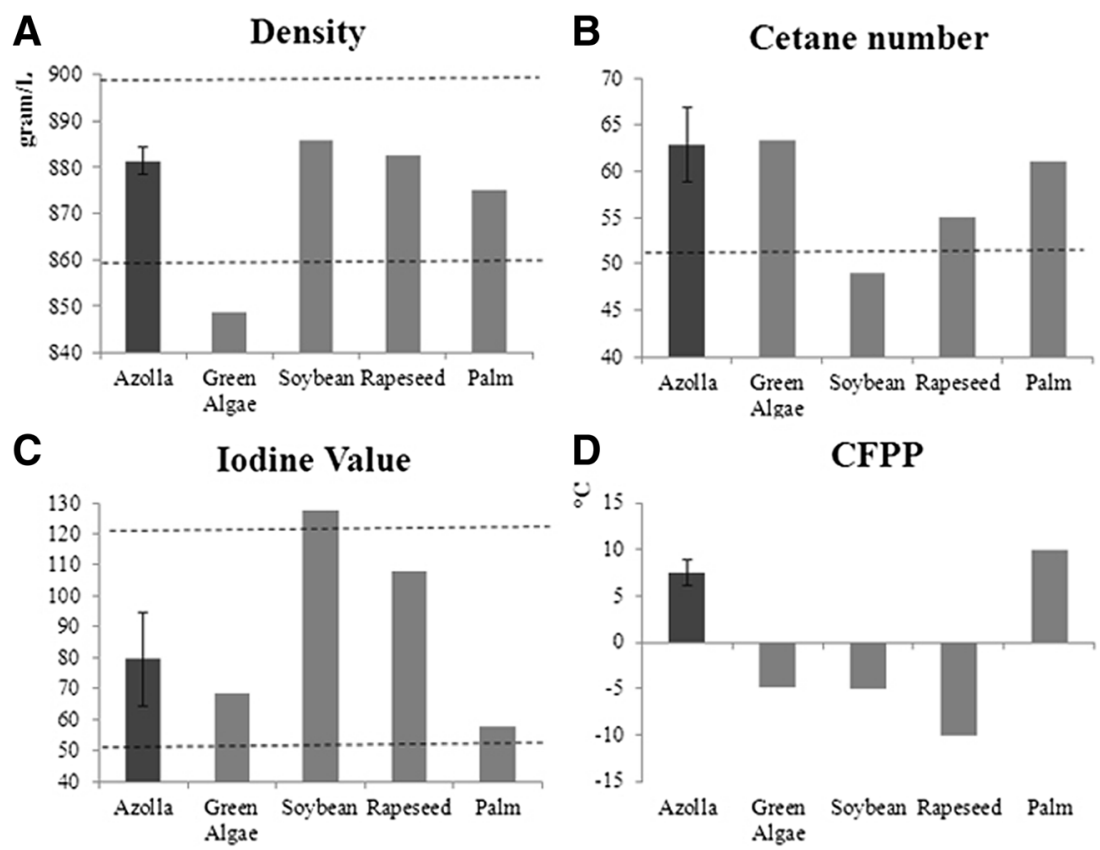

Azolla biodiesel, i.e. $7.5 \pm 1.4^{\circ} \mathrm{C}$, is too high for general operating conditions. This is mainly the result of the relatively high content of lignoceric (C24:0) in Azolla biomass, i.e., 3.4 $\pm 0.32 \%$ of the FAME fraction.

As the numerical models employed are limited to the FA profile, they do not take into account the effects of other lipid constituents. The mid-chain (di)hydroxy compounds amount to $7.2 \pm 2.8 \%$ of the crude lipid fraction. Although exact temperature characteristics are unknown, the high chain length, lack of double bonds, and GC behavior indicate that these compounds have high melting points and can therefore be a serious source of filter plugging and wax settling issues. Hence, fractionation into a FAME fraction and a fraction containing the high melting point midchain (di)hydroxy compounds will be necessary to ensure biodiesel quality in terms of cold temperature characteristics. To enhance the CFPP, this fractionation step may be extended to remove the C24:0 FA. Removal of C24:0 by crystallization fractionation and solvent fractionation was demonstrated by Pérez et al. [32] in the case of peanut biodiesel. In the case of Azolla, full removal up to C24:0 FA would lead to a drastic decrease in CFPP to $-12 \pm$ $0.83{ }^{\circ} \mathrm{C}$, while density, cetane number, and iodine value would change only slightly and remain within EU limits at $880 \pm 5.2 \mathrm{~kg} \mathrm{~m}^{-3}, 61.0 \pm 3.9$, and $82 \pm 16$, respectively. Hence, with added processing, high-quality biodiesel can be produced from the Azolla lipid fraction. Although an additional fractionation step infers additional costs, the second fraction rich in mid-chain (di)hydroxy compounds may also provide a second product stream, when the unique long-chain fatty alcohols, i.e., (di)OH alcohols, and
(di)OH FAs find applications as biochemicals. Surfactants, often applied as detergents in washing and cleaning formulas, and various specialty chemicals are manufactured on the basis of fatty alcohols [33, 34]. However, the alcohols in Azolla have multiple hydroxy groups and a typical chain length of C26-C36, which is much longer than that of the long-chain alcohols produced from FAs or petroleum (C14 C24). In food industry, fatty alcohols with a more similar chain length, such as octacosanol, are currently sold as food additive, due to their cholesterol-lowering effect in animals and humans [35]. If the Azolla fatty alcohols exhibit a similar function, such an application could be of commercial interest.

$\mathrm{OH}$ FAs are, among others, used as surfactants, lubricants, and synthetic precursors in the polymer industry [36, 37]. They are difficult to synthesize via chemical routes due to inertness of the fatty acid chain [37]. Currently, the main commercially produced OH FA is ricinoleic acid (12-hydroxy-9octadenenoic acid), which is extracted from castor oil and used for, among others, the synthesis of polyurethanes (PUs) and diacids [36].

Hence, various possible applications of these compounds exist. Whether, in addition to biodiesel production, further separation of the fatty alcohols and (di)OH FAs is worthwhile depends on the value of the biochemical versus its processing costs. The fact that they have longer chain length and more hydroxy groups compared to currently commercialized compounds may result in a high product value but also makes it difficult to assess the commercialization potential of these compounds beforehand and therefore requires further research. 


\section{Conclusions}

The lipid fraction of Azolla was investigated in the context of biodiesel production. Biomass drying conditions do not affect lipid yield or composition, indicating that drying conditions may be freely chosen so that they are energetically optimal. After saponification in methanol $3.2 \pm 1.0 \% \mathrm{dw}$ of FAMEs are obtained. From the lipid composition, it is predicted that highquality biodiesel can be produced from the Azolla lipid fraction but requires an additional fractionation step to decrease the CFPP. The unique long-chain (di)hydroxy fatty acids and fatty alcohols that are separated in this fractionation step may provide a valuable secondary product stream when purified into biochemicals, with possible applications to chemical industry and nutrition.

Acknowledgments We acknowledge the financial support by Shell Global Solutions International and the LPP foundation. We also like to thank Climate-KIC for support via the AzoFaSt pathfinder project.

Open Access This article is distributed under the terms of the Creative Commons Attribution 4.0 International License (http:// creativecommons.org/licenses/by/4.0/), which permits unrestricted use, distribution, and reproduction in any medium, provided you give appropriate credit to the original author(s) and the source, provide a link to the Creative Commons license, and indicate if changes were made.

\section{References}

1. EPSO (2005) European plant science: a field of opportunities. J Exp Bot 56:1699-709

2. de Vries SC, van de Ven GWJ, van Ittersum MK, Giller KE (2010) Resource use efficiency and environmental performance of nine major biofuel crops, processed by first-generation conversion techniques. Biomass Bioenergy 34:588-601

3. Becerra M, Murgueitio E, Reyes G, Preston TR (1990) Azolla filiculoides as partial replacement for traditional protein supplements in diets for growing fattening pigs based on sugar cane juice. Livestock Res Rural Develop; 2: 15,16,17,18,19,20,21,22

4. Sah RN, Goyal SS, Rains DW (1989) Interactive effects of exogenous combined nitrogen and phosphorus on growth and nitrogen fixation by azolla. Plant Soil 117:1-8

5. Speelman EN, Van Kempen MML, Barke J, Brinkhuis H, Reichart GJ, Smolders AJP et al (2009) The Eocene arctic azolla bloom: environmental conditions, productivity and carbon drawdown. Geobiology 7:155-70

6. Wagner GM (1997) Azolla: a review of its biology and utilization. Bot Rev 63:1-26

7. Abdel-Tawwab M (2008) The preference of the omnivorousmacrophagous, Tilapia zillii (Gervais), to consume a natural freefloating fern, Azolla pinnata. J World Aquacult Soc 39:104-12

8. Alalade OA, Iyayi EA (2006) Chemical composition and the feeding value of Azolla (Azolla pinnata) meal for egg-type chicks. Int J Poult Sci 5:137-41

9. Leterme P, Londoño AM, Ordoñez DC, Rosales A, Estrada F, Bindelle J et al (2010) Nutritional value and intake of aquatic ferns
(Azolla filiculoides Lam. and Salvinia molesta Mitchell.) in sows. Anim Feed Sci Technol 155:55-64

10. Fasakin EA (1999) Nutrient quality of leaf protein concentrates produced from water fern (Azolla africana Desv) and duckweed (Spirodela polyrrhiza L. Schleiden). Bioresour Technol 69:185-7

11. Abbasi SA, Nipaney PC, Schaumberg GD (1990) Bioenergy potential of eight common aquatic weeds. Biol Wastes 34:359-66

12. Jain SK, Gujral GS, Jha NK, Vasudevan P (1992) Production of biogas from Azolla pinnata $\mathrm{R} . \mathrm{Br}$ and Lemna minor L.: effect of heavy metal contamination. Bioresour Technol 41:273-7

13. Moser BR, Vaughn SF (2012) Efficacy of fatty acid profile as a tool for screening feedstocks for biodiesel production. Biomass Bioenergy 37:31-41

14. Ramos MJ, Fernández CM, Casas A, Rodríguez L, Pérez A (2009) Influence of fatty acid composition of raw materials on biodiesel properties. Bioresour Technol 100:261-8

15. Lapuerta M, Rodríguez-Fernández J, de Mora EF (2009) Correlation for the estimation of the cetane number of biodiesel fuels and implications on the iodine number. Energy Policy 37: 4337-44

16. Lapuerta M, Rodríguez-Fernández J, Armas O (2010) Correlation for the estimation of the density of fatty acid esters fuels and its implications. A proposed biodiesel cetane index. Chem Phys Lipids 163:720-7

17. Arias-Peñaranda MT, Cristiani-Urbina E, Montes-Horcasitas C, Esparza-Garciia F, Torzillo G, Cañizares-Villanueva RO (2013) Scenedesmus incrassatulus CLHE-Si01: a potential source of renewable lipid for high quality biodiesel production. Bioresour Technol 140:158-64

18. Yadav S, Kumar S, Hussain Z, Suneja P, Yadav SK, Nizar MA et al (2012) Guizotia abyssinica (L.f.) cass.: an untapped oilseed resource for the future. Biomass Bioenergy 43:72-8

19. Hussain J, Ruan Z, Nascimento IA, Liu Y, Liao W (2014) Lipid profiling and corresponding biodiesel quality of Mortierella isabellina using different drying and extraction methods. Bioresour Technol 169:768-72

20. Paoletti C, Bocci F, Lercker G, Capella P, Materassi R (1987) Lipid composition of Azolla caroliniana biomass and its seasonal variation. Phytochemistry 26:1045-7

21. Speelman EN, Reichart G, de Leeuw JW, Rijpstra WIC, Sinninghe Damsté JS (2009) Biomarker lipids of the freshwater fern Azolla and its fossil counterpart from the Eocene Arctic Ocean. Org Geochem 40:628-37

22. Deinum B, Maassen A (1994) Effects of drying temperature on chemical composition and in vitro digestibility of forages. Anim Feed Sci Technol 46:75-86

23. Watanabe I, Roger PA, Ladha JK, van Hove C (1992) Biofertilizer germplasm collections at IRRI: International Rice Research Institute

24. CEN (2008) EN 14214 Automotive fuels - Fatty acid methyl esters (FAME) for diesel engines - Requirements and test methods

25. Poorter H, Van Berkel Y, Baxter R, Den Hertog J, Dijkstra P, Gifford RM et al (1997) The effect of elevated CO2 on the chemical composition and construction costs of leaves of $27 \mathrm{C} 3$ species. Plant, Cell Environ 20:472-82

26. Karmakar A, Karmakar S, Mukherjee S (2010) Properties of various plants and animals feedstocks for biodiesel production. Bioresour Technol 101:7201-10

27. Petkov G, Ivanova A, Iliev I, Vaseva I (2012) A critical look at the microalgae biodiesel. Eur J Lipid Sci Technol 114:103-11

28. Muradov N, Taha M, Miranda AF, Kadali K, Gujar A, Rochfort S, et al. (2014) Dual application of duckweed and azolla plants for wastewater treatment and renewable fuels and petrochemicals production. Biotechnology for Biofuels; 7 
29. Leung DYC, Wu X, Leung MKH (2010) A review on biodiesel production using catalyzed transesterification. Appl Energy 87: 1083-95

30. Berchmans HJ, Hirata S (2008) Biodiesel production from crude Jatropha curcas L. seed oil with a high content of free fatty acids. Bioresour Technol 99:1716-21

31. Toda M, Takagaki A, Okamura M, Kondo JN, Hayashi S, Domen K et al (2005) Green chemistry: biodiesel made with sugar catalyst. Nature 438:178

32. Pérez A, Casas A, Fernández CM, Ramos MJ, Rodríguez L (2010) Winterization of peanut biodiesel to improve the cold flow properties. Bioresour Technol 101:7375-81
33. Biermann U, Bornscheuer U, Meier MAR, Metzger JO, Schäfer HJ (2011) Oils and fats as renewable raw materials in chemistry. Angewandte Chemie - Int Edition 50:3854-71

34. Behr A, Westfechtel A, Pérez GJ (2008) Catalytic processes for the technical use of natural fats and oils. Chem Eng Technol 31:700-14

35. Hargrove JL, Greenspan P, Hartle DK (2004) Nutritional significance and metabolism of very long chain fatty alcohols and acids from dietary waxes. Exp Biol Med 229:215-26

36. Mutlu H, Meier MAR (2010) Castor oil as a renewable resource for the chemical industry. Eur J Lipid Sci Technol 112:10-30

37. Cao Y, Zhang X (2013) Production of long-chain hydroxy fatty acids by microbial conversion. Appl Microbiol Biotechnol 97:3323-31 